\title{
Analysis of Thin Isotropic Rectangular and Circular Plates with Multiquadrics
}

\author{
A. J. M. Ferreira, C. M. C. Roque, and P. A. L. S. Martins \\ Departamento de Engenharia Mecânica e Gestão Industrial Faculdade de Engenharia, \\ Universidade do Porto, Porto, Portugal
}

удК 539.4

\section{Анализ тонких изотропных прямоугольных и круглых пластин методом мультиквадратических функций}

\author{
А. Ж. М. Феррейра, С. М. С. Рок, П. А. Л. С. Мартинс
}

Университет г. Порто, Португалия

Выполнен линейный расчет напряженно-деформированного состояния тонких пластин численныл методом, базирующемся на использовании мультиквадратических радиальньх базисньх функций. Показано, что данньй метод оказывается весьма гибким при расчетах объектов со сложной геометрией, поскольку не требует сеточного разбиения и нечувствителен к их пространственньл координатал. Полученнье численнье результать сравниваются с данньми решений на основе теории пластин Кирхгофа.

Ключевые слова: численный метод, напряженно-деформированное состояние, тонкие пластины, мультиквадратические функции, радиальные базисные функции, несимметричная коллокация.

Introduction. The purpose of this paper is the application of radial basis functions, to the analysis of thin plates. Hardy [1] was the first to develop the multiquadrics method (MQ) as a general scattered data approximation algorithm to approximate two-dimensional geographical surfaces. The MQ method was found to be one of the best interpolation schemes for scattered data by Franke [2]. The method used in this paper is based on the work of Kansa [3] where a modified MQ scheme was proposed for the solution of partial differential equations. The numerical solution of partial differential equations (PDEs) is traditionally dominated by finite element methods, finite volume methods or finite difference methods. All of these methods are based on local interpolation strategies and depend on a mesh for local approximation. In these methods although the function is continuous across meshes, its partial derivatives are not [4-6]. The MQ method depends on the distance to a center point $\mathbf{x}_{j}$ and is of the form $g\left(\left\|\mathbf{x}-\mathbf{x}_{j}\right\|\right)$. The radial basis functions (RBF) may also depend on a shape parameter $c$, in which case $g\left(\left\|\mathbf{x}-\mathbf{x}_{j}\right\|\right)$ is replaced by $g\left(\left\|\mathbf{x}-\mathbf{x}_{j}\right\|, c\right)[3,7]$. The multiquadrics solution depends of the choice of the shape parameter, a user-defined parameter. This choice is still an open discussion. This method was 
previously applied with success to some engineering problems [8] and to composite materials by Ferreira et al. [9-11].

In this paper it is investigated the application of the MQ method in the solution of thin plates, which is a relevant problem for mechanical, civil and structural engineers. The numerical solutions are compared with Kirchhoff theory.

1. The Multiquadric Method. Consider a set of nodes $x_{1}, x_{2}, \ldots, x_{N} \in$ $\Omega \subset R^{n}$. The radial basis functions centered at $\mathbf{x}_{j}$ are defined as

$$
g_{j}(\mathbf{x}) \equiv g\left(\left\|\mathbf{x}-\mathbf{x}_{j}\right\|\right) \in R^{n}, \quad j=1, \ldots, N,
$$

where $\left\|\mathbf{x}-\mathbf{x}_{j}\right\|$ is the Euclidian norm. Some of the most common RBFs are

$$
\text { multiquadrics: } g_{j}(\mathbf{x})=\left(\left\|\mathbf{x}-\mathbf{x}_{j}\right\|^{2}+c^{2}\right)^{1 / 2} \text { : }
$$

$$
\text { inverse multiquadrics: } g_{j}(\mathbf{x})=\left(\left\|\mathbf{x}-\mathbf{x}_{j}\right\|^{2}+c^{2}\right)^{-1 / 2} \text {, }
$$

$$
\text { Gaussians: } g_{j}(\mathbf{x})=e^{-c^{2}\left\|\mathbf{x}-\mathbf{x}_{j}\right\|^{2}} \text {, }
$$

thin-plate splines: $g_{j}(\mathbf{x})=\left\|\mathbf{x}-\mathbf{x}_{j}\right\|^{2 m} \log \left\|\mathbf{x}-\mathbf{x}_{j}\right\|, \quad m=1,2, \ldots, n$,

where $c$ is a shape (user-defined) parameter.

In this paper we will concentrate on the multiquadrics approach. Radial basis functions are insensitive to spatial dimension, making the implementation of this method much easier than, e.g., finite elements. Illustration of a network of nodes is given in Fig. 1.

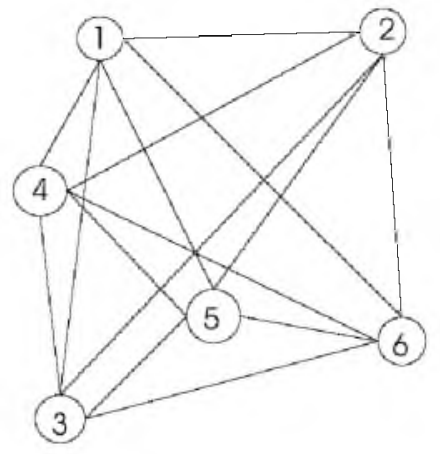

Fig. 1. Illustration of a network of nodes.

An important feature of the RBF method is that is does not require a grid. The only geometric properties needed in an RBF approximation are the pairwise distances between points. Working with higher dimensional problems is not difficult as distances are easy to compute in any number of space dimensions. 
In this paper, it is proposed to use Kansa's unsymmetric collocation method [3]. Consider a boundary-valued problem with a domain $\Omega \subset R^{n}$ and a linear elliptic partial differential equation of the form

$$
\begin{gathered}
L u(x)=s(x) \subset R^{n}, \\
B u(x)_{\mid \partial \Omega}=f(x) \in R^{n},
\end{gathered}
$$

where $\partial \Omega$ represents the boundary of the problem. We use points along the boundary $\left(\mathbf{x}_{j}, j=1, \ldots, N_{B}\right)$ and in the interior $\left(\mathbf{x}_{j}, j=N_{B}+1, \ldots, N\right)$.

Let the RBF interpolant to the solution $u(\mathbf{x})$ be

$$
s(\mathbf{x}, c)=\sum_{j=1}^{N} a_{j} g\left(\left\|\mathbf{x}-\mathbf{x}_{j}\right\|, c\right) .
$$

Collocation with the boundary data at the boundary points and with PDE at the interior points leads to equations

$$
\begin{gathered}
s_{B}(\mathbf{x}, c)=\sum_{j=1}^{N} a_{j} \operatorname{Bg}\left(\left\|\mathbf{x}-\mathbf{x}_{j}\right\|, c\right)=\lambda\left(\mathbf{x}_{i}\right), \quad i=1, \ldots, N_{B}, \\
s_{L}(\mathbf{x}, c)=\sum_{j=1}^{N} a_{j} \operatorname{Lg}\left(\left\|\mathbf{x}-\mathbf{x}_{j}\right\|, c\right)=\Phi\left(\mathbf{x}_{i}\right), \quad i=N_{B}+1, \ldots, N,
\end{gathered}
$$

where $\lambda\left(\mathbf{x}_{i}\right)$ and $\Phi\left(\mathbf{x}_{i}\right)$ are the prescribed values at the boundary nodes and the function values at the interior nodes, respectively.

This corresponds to a system of equations with an unsymmetric coefficient matrix, structured in matrix form as

$$
\left[\begin{array}{l}
B \mathbf{g} \\
L \mathbf{g}
\end{array}\right][\mathbf{a}]=\left[\begin{array}{l}
\lambda \\
\Phi
\end{array}\right]
$$

\section{Thin Plate Analysis.}

2.1. Thin Plate Theory. It is considered a thin plate, subjected to lateral transverse loads $q=q(x, y)$. The symbol $D$ is used to represent the flexural rigidity of the plate:

$$
D=\frac{E h^{3}}{12\left(1-v^{2}\right)} \text {. }
$$

In the plate problem, the unknown transverse displacement, $w$, is calculated by solving the boundary-valued problem, defined by the differential equation: 


$$
\frac{\partial^{4} w}{\partial x^{4}}+2 \frac{\partial^{4} w}{\partial x^{2} \partial y^{2}}+\frac{\partial^{4} w}{\partial y^{4}}=\frac{q(x, y)}{D} \text {. }
$$

The boundary conditions are defined, for example, for a simply-supported edge parallel to the $x$-axis at $y=b$ as

$$
[w]_{y=b}=0,\left[\frac{\partial^{2} w}{\partial x^{2}}\right]_{y=b}=0 .
$$

The flexural moments are obtained by

$$
\begin{gathered}
M_{x}=-D\left(\frac{\partial^{2} w}{\partial x^{2}}+v \frac{\partial^{2} w}{\partial y^{2}}\right), \\
M_{y}=-D\left(v \frac{\partial^{2} w}{\partial x^{2}}+\frac{\partial^{2} w}{\partial y^{2}}\right), \\
M_{x y}=D(1-v) \frac{\partial^{2} w}{\partial x \partial y} .
\end{gathered}
$$

2.2. Multiquadrics Interpolation for the Governing Equation. Applying the multiquadrics method previously explained, the differential equation (13) is now interpolated for each node $i$, as

$$
\sum_{j=1}^{N \times N} \phi_{j}\left[\frac{\partial^{4} g_{j}}{\partial x^{4}}+2 \frac{\partial^{4} g_{j}}{\partial x^{2} \partial y^{2}}+\frac{\partial^{4} g_{j}}{\partial y^{4}}\right]=\frac{q(x, y)}{D}
$$

where $g_{i}$ was defined in Eq. (1).

2.3. Multiquadrics Interpolation for Boundary Conditions. For each boundary node, the multiquadric interpolation for each boundary node follows the approach in Eq. (8). A simply-supported condition in $x=a$ edge imposes two boundary conditions (see Fig. 2)

$$
w_{x=a}=0 \quad \text { and } \quad \frac{\partial^{2} w}{\partial x^{2}}+v \frac{\partial^{2} w}{\partial y^{2}}=0 .
$$

In this collocation method, we chose to impose the first boundary condition on node with $x=a$ and the second boundary condition on node with $x=a \pm \delta$ when $\delta$ is a very small number. This approach was previously applied by Jang et al. [13] to differential quadrature method on plates. It is really important to apply this methodology due to the improvement of the quality of solution when 
$\delta$ is used. The collocation points, after the inclusion of $\delta$, can be seen on Fig. 3, for various point cloud density.

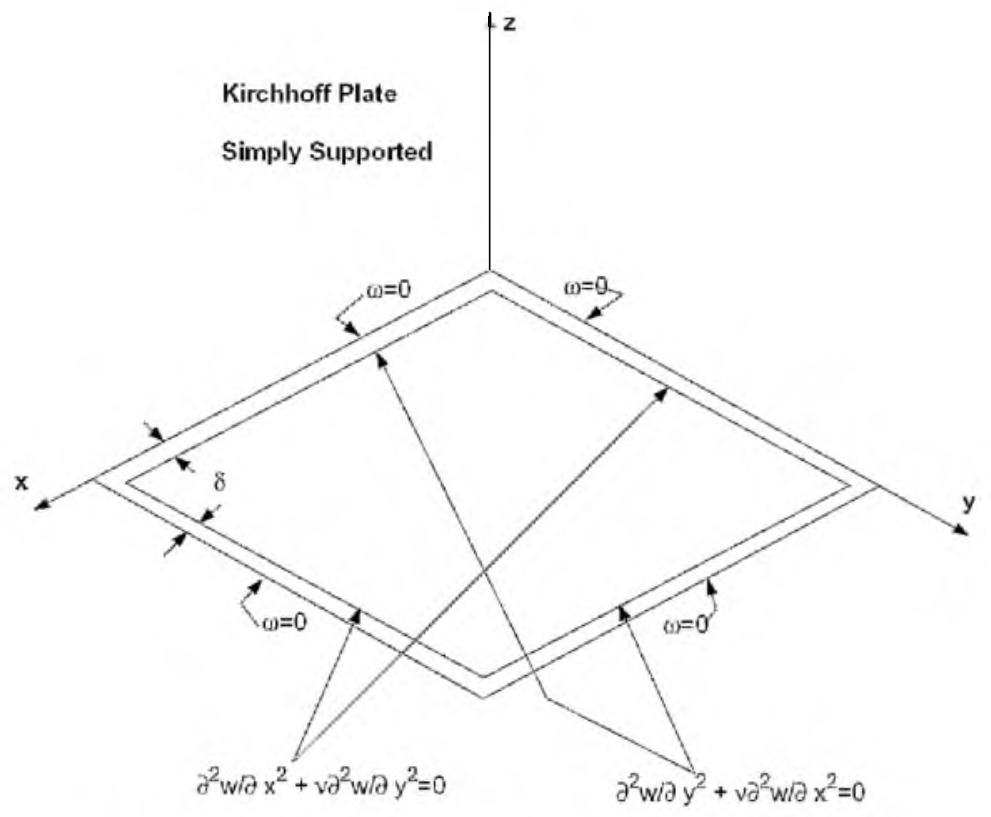

Fig. 2. Boundary conditions for a simply-supported plate.
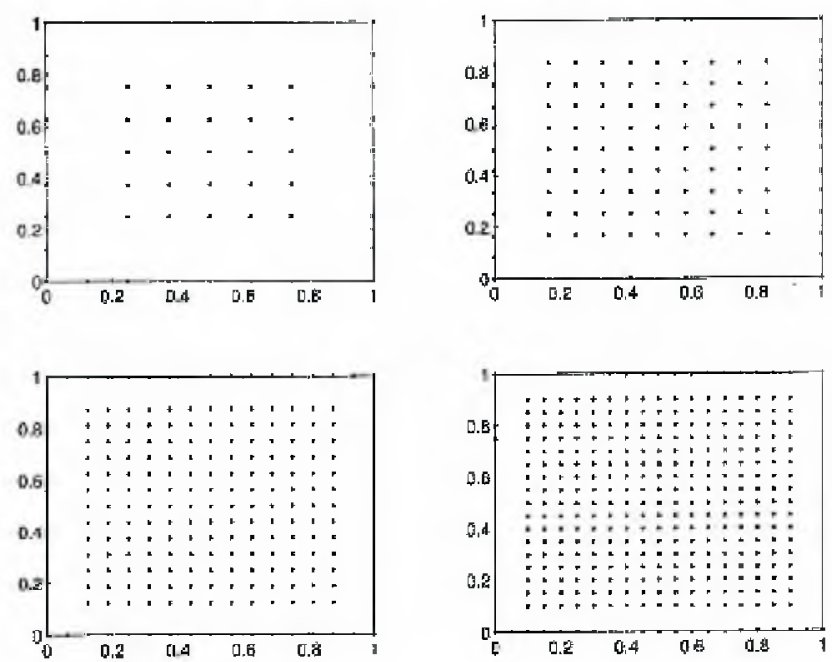

Fig. 3. Regular discretization for $N=9,13,17$, and 21 .

The multiquadrics interpolation of equations (19) leads to a change in the global equations system. As an example, for each node $i$ where $w=0$, the following multiquadric equation is imposed:

$$
\sum_{j=1}^{N \times N} \phi_{j} \sqrt{\left(x_{i}-x_{j}\right)^{2}+\left(y_{i}-y_{j}\right)^{2}+c^{2}}=0 .
$$


3. Discussion of Results. The analysis of square and circular Kirchhoff plates is performed, for simply-supported and clamped conditions. All plates are subjected to a uniform unit load. Square plates have unit side and circular plates have unit radius.

In figures below, $N$ is considered as the number of nodes per side in square plates and the number of nodes per radius in circular plates. In all problems a unit bending stiffness is considered. The objective of the numeric studies is to evaluate the accuracy of the model with exact Kirchhoff results, as presented by Timoshenko [12].

The influence of various parameters in the quality of the solutions is investigated. In particular the effect of the shape-parameter, $c$, and the $\delta$ parameter in the solution error are considered.

The root-mean-square error (RMS) was calculated using:

$$
R M S=\frac{1}{N \times N-N_{B}} \sum_{j=1}^{N \times N-N_{B}} \sqrt{\left(\frac{w_{\text {exact }}-w_{M Q}}{w_{\text {exact }}}\right)^{2}} .
$$

Solutions for the transverse displacement curve are presented.

In Fig. 4 it is illustrated the deformed shape of a simply-supported square plate, for $N=23$, and $\delta=1 \cdot 10^{-7}$. It can be seen a very smooth deformation pattern, that presents very accurate forms when compared with exact solution as can be seen in Fig. 5 where an error study is conducted. In this figure it is presented the evaluation of the root-mean-square error with $N$. The convergence to exact results is exponential. After about 20 nodes per side the solution is almost exact, with very small RMS error.

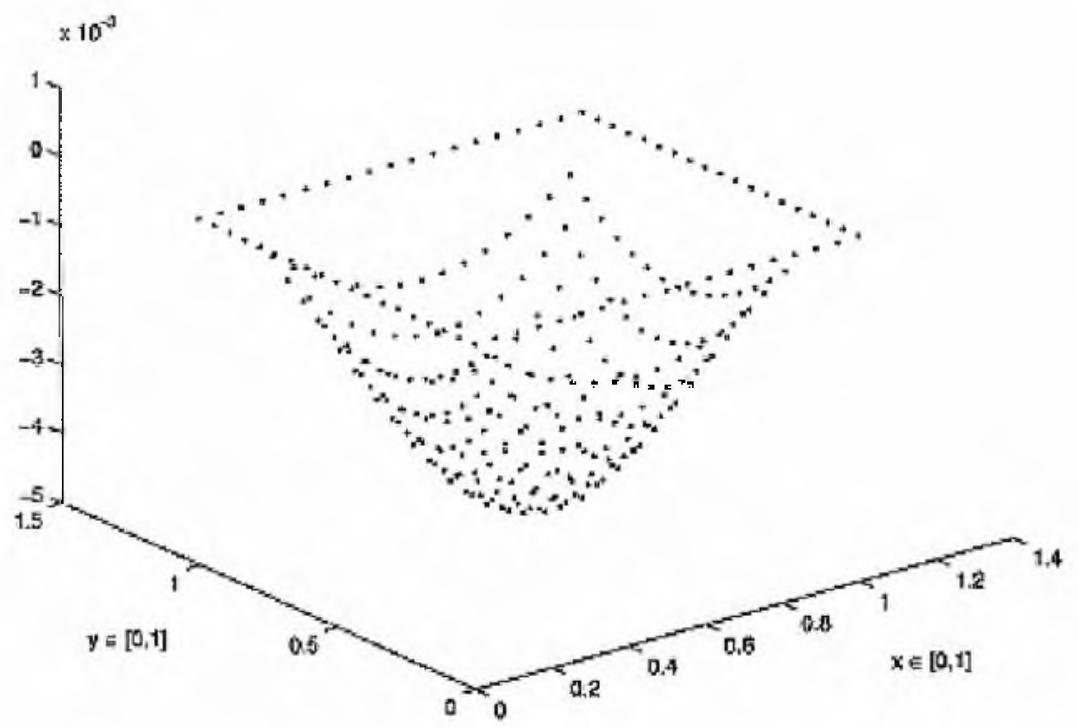

Fig. 4. Transverse displacement for a simply supported square plate with $N=21, \delta=10^{-7}$, and $c=2 / \sqrt{N}$. 
Further calculation for square plates considered $N=19$ due to the good behavior as seen in Fig. 5.

The influence of shape-parameter $c$ in the RMS error is plotted in Fig. 6. All values of $c \in[0,1]$ produce errors around $10^{-3}$. However, values in range $[0.4-1.0]$ should be preferred. Our usual choice is $c=2 / \sqrt{N}$, which matches this interval and in fact produces one of the smallest error. This choice was previously proposed by Fasshauer [7].

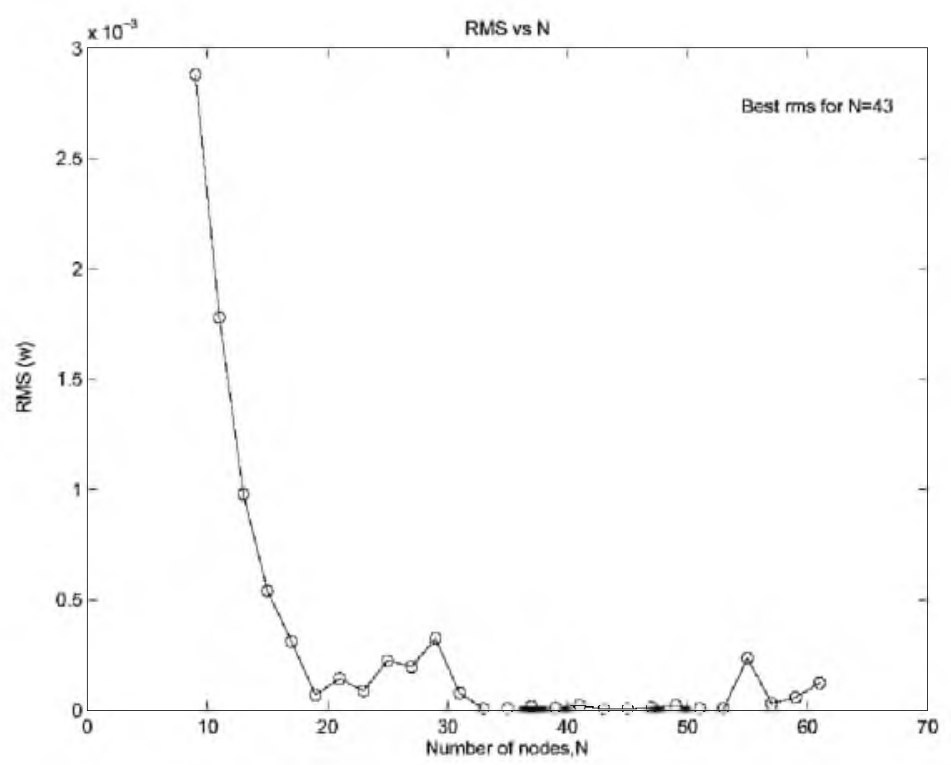

Fig. 5. RMS error dependence on $N$ for a simply supported square plate with $\delta=1 \cdot 10^{-5}$ and $c=2 / \sqrt{N}$.

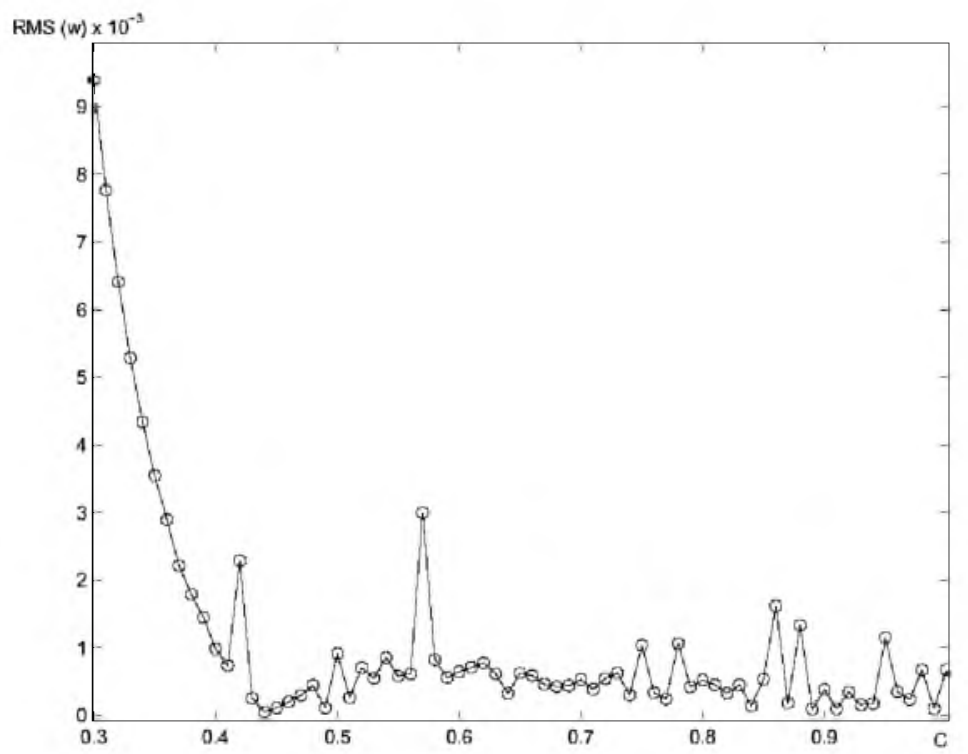

Fig. 6. RMS error dependence on $c$ for a simply supported square plate with $N=19$ and $\delta=1 \cdot 10^{-5}$. 
Figure 7 plot the variation of RMS error with $\delta$ parameter. This parameter is necessary to adequately introduce the second set of boundary conditions and needs to be a very small number. The variation of RMS error with $\delta$ is in general linear, with a few exceptions.

The evaluation of RMS error for the transverse displacement with $N$ is plotted in Fig. 8. A very fast convergence is obtained. A good solution quality is obtained after 18 points per side.

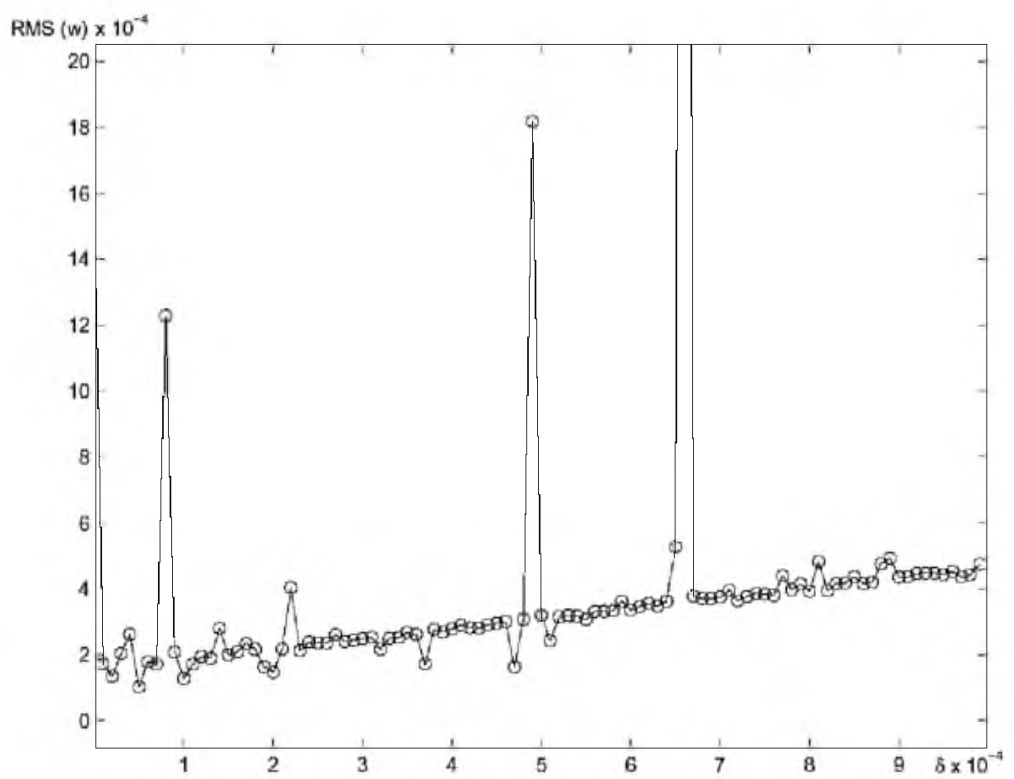

Fig. 7. RMS error dependence on $\delta$ for a simply supported square plate with $N=19$ and $c=2 / \sqrt{N}$.

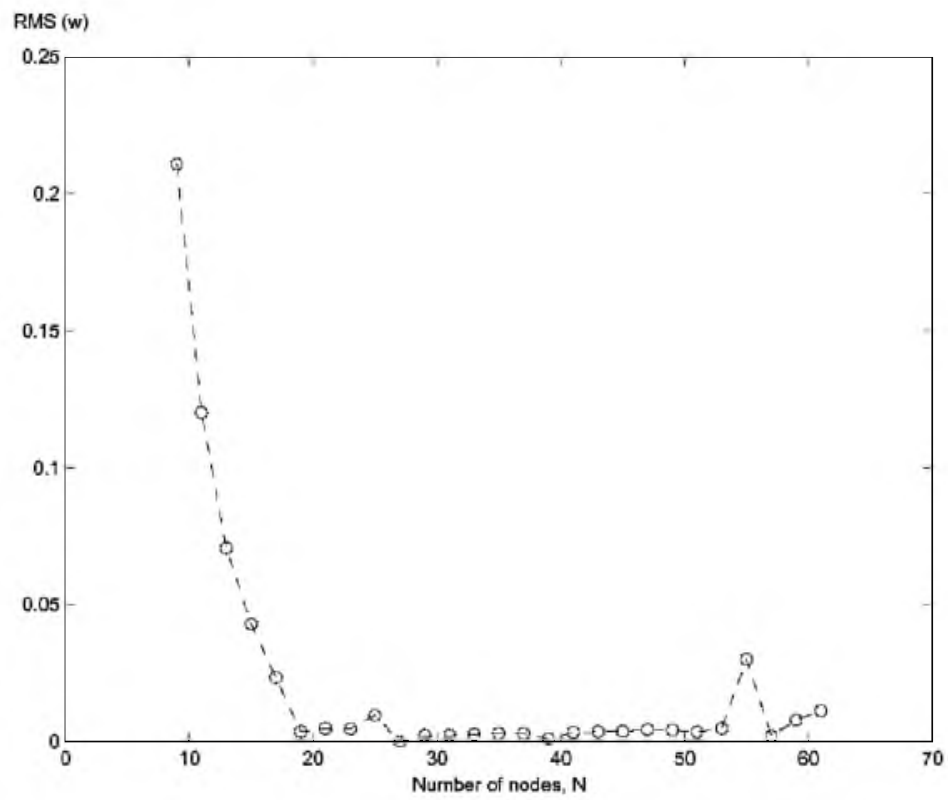

Fig. 8. RMS error dependence on $N$ for a clamped square plate with $\delta=1 \cdot 10^{-5}$ and $c=2 / \sqrt{N}$. 
In Figs. 9 and 10 the evaluation of RMS with $c$ and RMS with $\delta$ are plotted. The results follow the same good pattern as for simply-supported plates.

In Fig. 11 are illustrated some meshes of circular plates for various 'mesh' densities. Near the external boundary nodes a new set of nodes is placed in order to apply a second set of boundary conditions. This ' $\delta$-approach' already used by Jang et al. [13] will affect significantly the quality of the solution as will be seen in figures below.

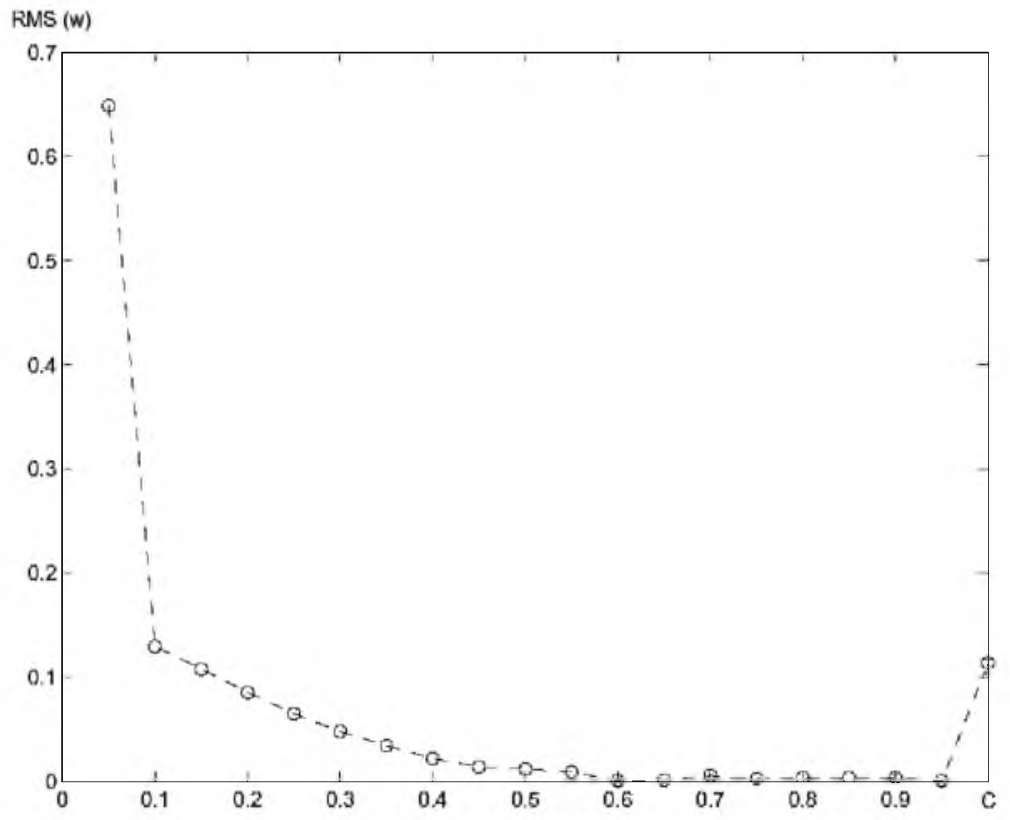

Fig. 9. RMS error dependence on $c$ for a simply supported square plate with $N=19$.

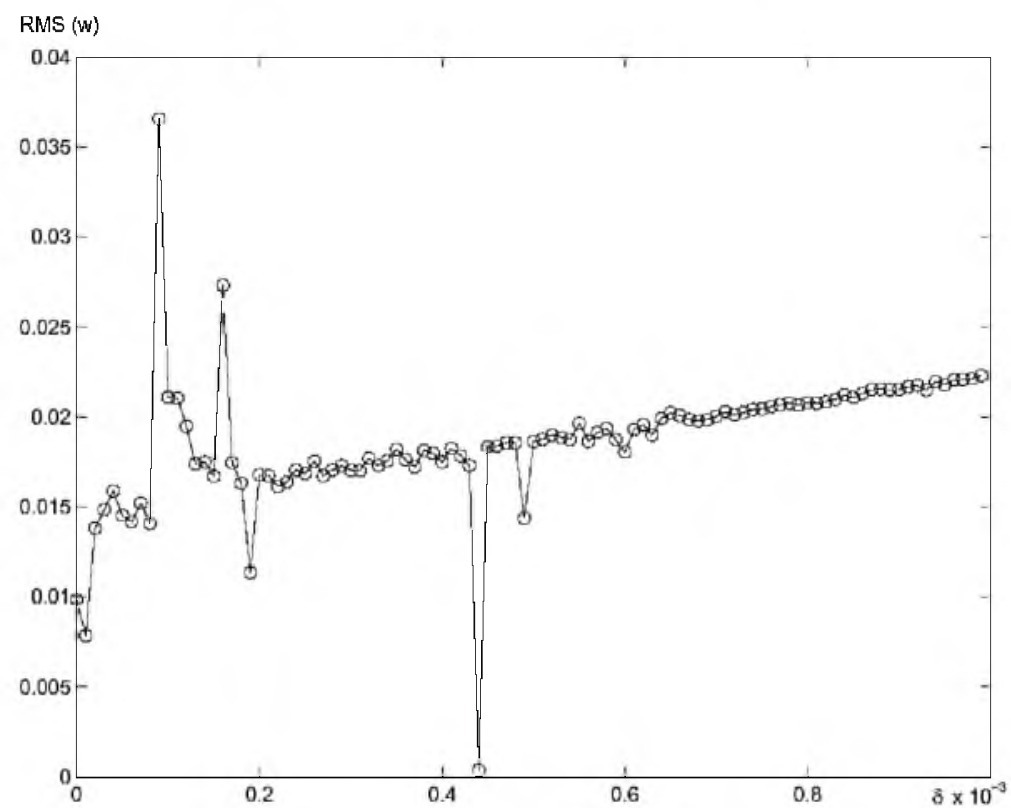

Fig. 10. RMS error dependence on $\delta$ for a clamped square plate with $N=19$ and $c=2 / \sqrt{N}$. 
In Fig. 12 the vertical (transverse) displacement for each node is plotted, corresponding to a cloud of nodes representing the deformation of the plate. The deformation of the plate is presented for $N=23$ for a simply-supported plate. $N$ represents the number of nodes in a single radius of the plate.
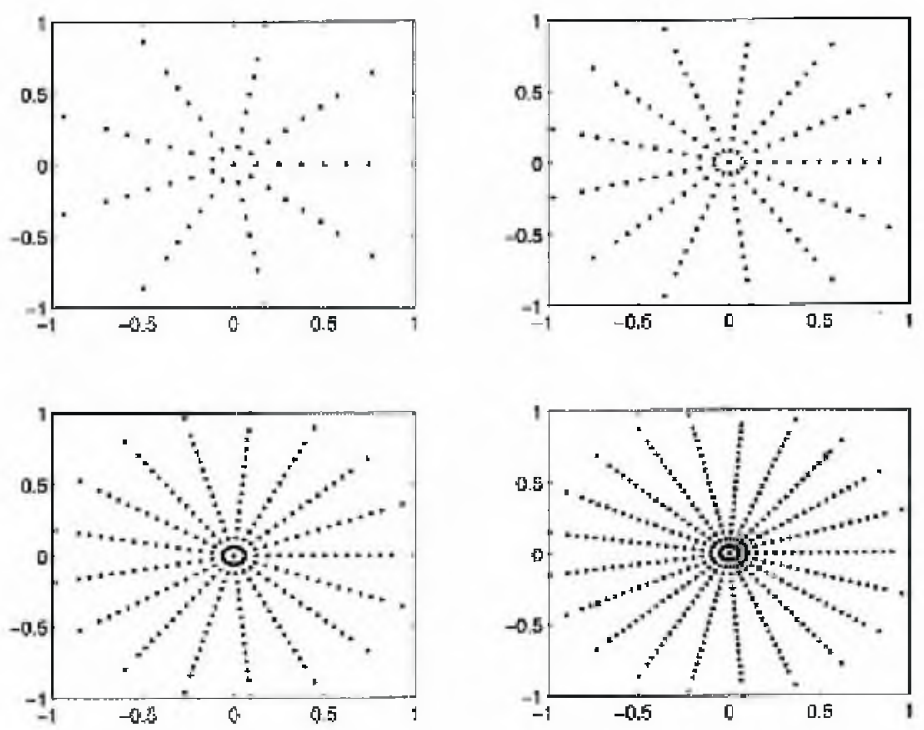

Fig. 11. Regular discretization for a circular plate with $N=8,12,16$, and 20 .

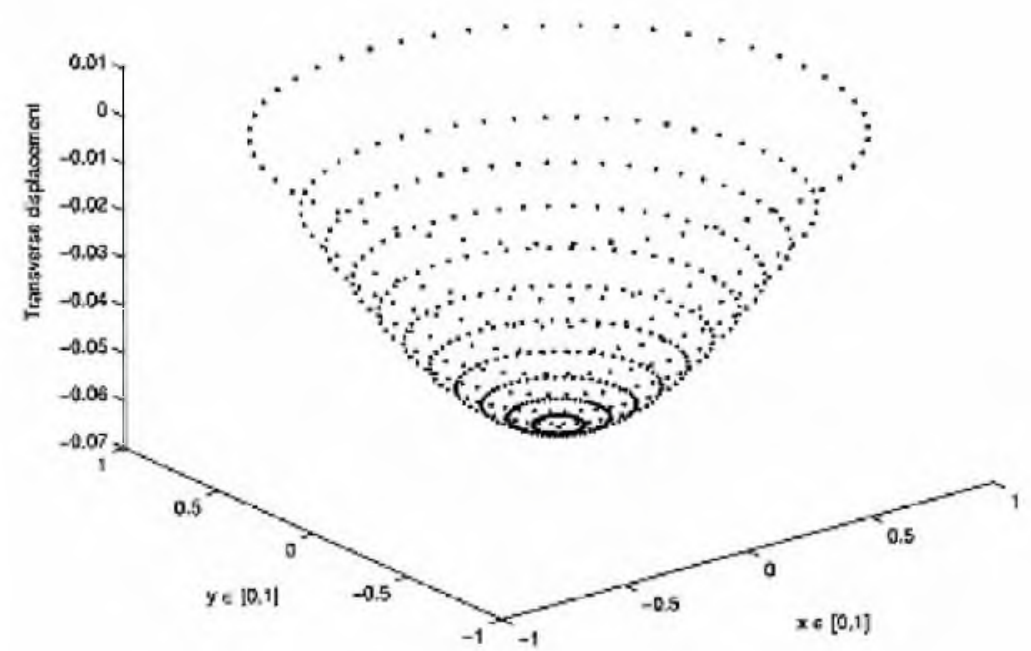

Fig. 12. Regular discretization for a simply supported circular plate with $N=13, \delta=k / 100$, and $c=2 / \sqrt{N}$.

In Fig. 13 the evolution of root-mean-square curve (transverse displacement) with the shape parameter $c$ is presented for simply-supported circular plates Similar curves are obtained for $N=11,19,25$. There is a fast convergence to final results for every $N$.

The RMS error was calculated only for node where maximum displacement is taking place using: 


$$
R M S=\frac{1}{N \times N-N_{B}} \sum_{j=1}^{N \times N-N_{B}} \sqrt{\left(\frac{w_{\max , \text { exact }}-w_{\max , M Q}}{w_{\max , \text { exact }}}\right)^{2}} .
$$

Keeping $\delta=k / 100$, the evolution of RMS error with the shape-parameter for clamped circular plate is illustrated in Fig. 14, for various grids. Significant dependence of RMS error is noticeable. However, for $N>9, c>0.2$ very small errors are produced. In particular, $c=2 / \sqrt{N}$ is included in such range which confirms the results of Fasshauer [7].

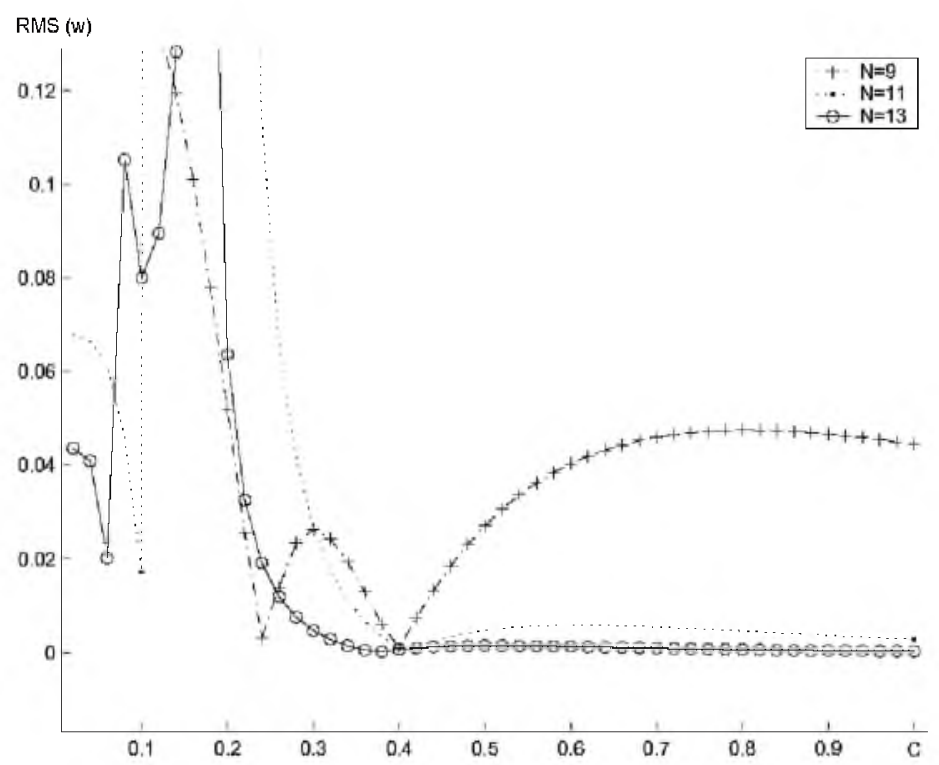

Fig. 13. RMS error dependence on $c$ for a simply supported circular plate $\delta=k / 100$.

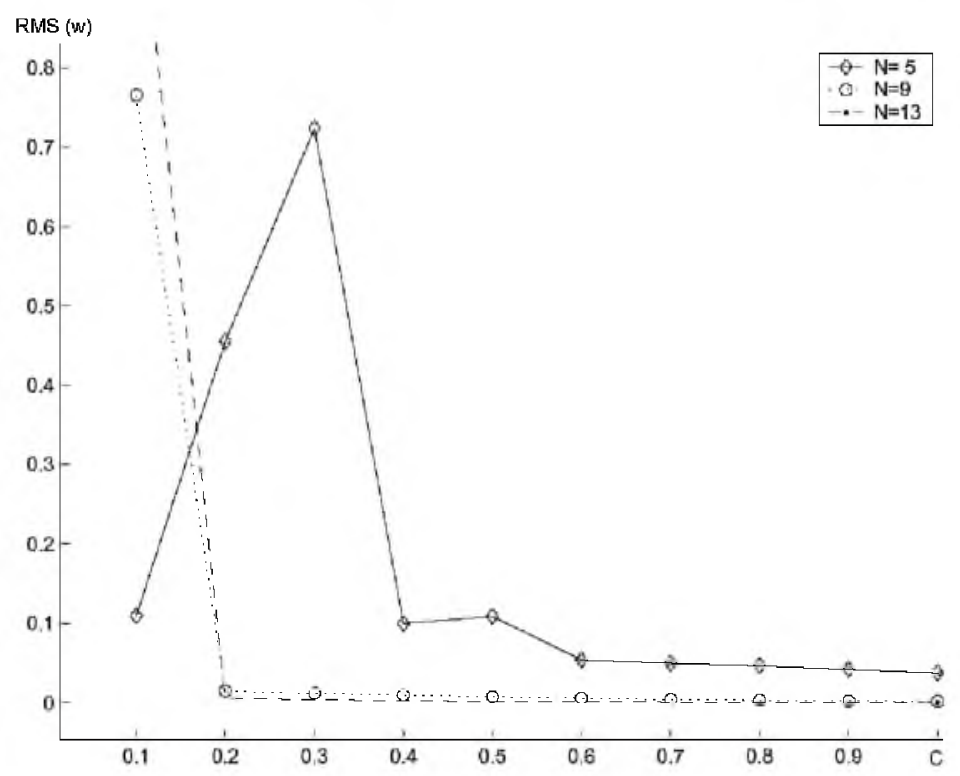

Fig. 14. RMS error dependence on $c$ for a clamped circular plate $\delta=k / 100$. 
In Tables 1 and 2, the results from the present model and the exact (Kirchhoff) values [12] are presented. In Table 1, the results are presented for simply-supported and clamped square plates. In Table 2, the results are presented for simply-supported and clamped circular plates. The present results are in very good agreement with exact values.

$\mathrm{T}$ a b 1 e 1

Model and Exact Values of $w$ and $M_{x}$ for Thin Square Plates

\begin{tabular}{|c|c|c|c|c|}
\hline \multirow{2}{*}{} & \multicolumn{2}{|c|}{$\begin{array}{c}\text { Simply supported } \\
\delta=10^{-7}\end{array}$} & \multicolumn{2}{c|}{$\begin{array}{c}\text { Clamped } \\
\delta=10^{-7}\end{array}$} \\
\hline$N$ & $w(0,0)$ & $M_{x}(0,0)$ & $w(0,0)$ & $M_{x}(0,0)$ \\
\hline 10 & 0.0039329 & 0.046740 & 0.00100 & 0.0196 \\
\hline 15 & 0.0040110 & 0.047431 & 0.00110 & 0.0890 \\
\hline 21 & 0.0040104 & 0.047436 & 0.00120 & 0.0225 \\
\hline Exact & 0.0041600 & 0.047900 & 0.00126 & 0.0231 \\
\hline
\end{tabular}

$\mathrm{T}$ a $\mathrm{b} 1$ e 2

Model and Exact Values of $w$ and $M_{x}$ for Thin Circular Plates

\begin{tabular}{|c|c|c|c|c|}
\hline \multirow{2}{*}{} & \multicolumn{2}{|c|}{$\begin{array}{c}\text { Simply supported } \\
\delta=k / 100\end{array}$} & \multicolumn{2}{c|}{$\begin{array}{c}\text { Clamped } \\
\delta=r / 100\end{array}$} \\
\hline$N$ & $w(r=0)$ & $M_{x}(r=0)$ & $w(r=0)$ & $M_{x}(r=0)$ \\
\hline 6 & 0.0510 & 0.1727 & 0.0132 & 0.0740 \\
\hline 10 & 0.0599 & 0.1962 & 0.0150 & 0.0796 \\
\hline 14 & 0.0622 & 0.2023 & 0.0154 & 0.0807 \\
\hline 16 & 0.0627 & 0.2036 & 0.0155 & 0.0809 \\
\hline Exact & 0.0637 & 0.2062 & 0.0156 & 0.0813 \\
\hline
\end{tabular}

Conclusions. In this paper, the multiquadrics method was applied to the structural analysis of square and circular plates. The method is most adequate to analyze any geometry with the same governing equations provided adequate boundary conditions are imposed. The quality of the solution converges exponentially for both square and circular plates. Given the collocation procedure, a ' $\delta$-approach' was used in order to impose a second set of boundary conditions. This procedure provides a significant improvement in the quality of the solution. In general, the model agrees very well with the exact Kirchhoff theory for plates. This method can be a good alternative to the finite element method and to the finite difference method in the analysis of such structures.

\section{Р е 3 юм е}

Виконано лінійний розрахунок напружено-деформованого стану тонких пластин числовим методом, що базується на використанні мультіквадратичних радіальних базисних функцій. Показано, що даний метод $€$ досить гнучким при розрахунках об'єктів зі складною геометрією, оскільки не потребує 
сіткового розбиття і нечутливий до іх просторових координат. Отримані числові результати порівноються 3 даними розв'язків на основі теорії пластин Кірхгофа.

1. R. L. Hardy, "Multiquadric equations of topography and other irregular surfaces," Geophys. Res., 176, 1905-1915 (1971).

2. R. Franke, "Scattered data interpolation: test of some methods," Math Comput., 38, 181-200 (1982).

3. E. J. Kansa, "Multiquadrics - a scattered data approximation scheme with applications to computational fluid dynamics. Pt. I: Surface approximations and partial derivative estimates," Comput. Math. Appl., 19, No. 8/9, 127-145 (1990).

4. O. C. Zienkiewicz, The Finite Element Method, McGraw-Hill (1991).

5. T. J. R. Hughes, The Finite Element Method - Linear Static and Dynamic Finite Element Analysis, Dover Publications, New York (2000)

6. K. J. Bathe, Finite Element Procedures in Engineering Analysis, Prentice Hall (1982)

7. G. E. Fasshauer, "Solving partial differential equations by collocation with radial basis functions, surface fitting and multiresolution methods," in: Proc. of the 3rd Int. Conf. on Curves and Surfaces (1997), Vol. 2, pp. 131-138.

8. Y. C. Hon, K. F Cheung, X. Z. Mao, and E. J. Kansa, "A multiquadric solution for the shallow water equation," ASCE J. Hydr. Eng., 125, No. 5, 524-533 (1999).

9. A. J. M. Ferreira, "A formulation of the multiquadric radial basis function method for the analysis of laminated composite plates," Composite Struct., 59, 385-392 (2003).

10. A. J. M. Ferreira, "Thick composite beam analysis using a global meshless approximation based on radial basis functions," Mech. Adv. Mater. Struct., 10, No. 3, 271-284 (2003).

11. A. J. M. Ferreira, C. M. C. Roque, P. A. L. S. Martins, "Analysis of composite plates using higher-order shear deformation theory and a finite point formulation based on the multiquadric radial basis function method," Composites-Part B: Engineering, 34, 627-636 (2003).

12. S. P. Timoshenko and S. Woinowsky-Krieger, Theory of Plates and Shells, 2nd Edition, McGraw-Hill Int. Student Edition (1959).

13. S. K. Jang, C. W. Bert, and A. G. Striz, "Application of differential quadrature to static analysis of structural components," IJNME, 28, 561-577 (1989). 